\title{
Work Stress in Banking Sectors in Pakistan
}

\author{
Dr.NadeemBhatti
}

68 Corporate Drive, Suite \# 1626 Scarborough, ON, M1H 3H3, Canada

nadbhatti@yahoo.com, Ph. 01-416-575-6024

\section{Dr.Anwar Ali Shah G.Syed}

\section{PVC-Sindh University Campus Dadu Faiz Muhammad Shaikh Assistant Professor-SZABAC- Dokri}

\section{Email:faizmuhammed_2000@yahoo.com}

\section{Dr.MunirAhmadani}

Assistant Professor-Deptt: of Commerce Govt-Commerce College Hyderabad

\begin{abstract}
Stress has been experienced since ancient times, but it has never been worse than it is here in the early 21 st century. Nowadays stress is responsible for more than fifty percent of all illness. Despite this fact, the phenomenon of stress still hasn't been that deeply studied. Contemporary society has to deal with the relatively new concept of workplace stressmore and more often. In order to answer the questions as to Why and What to do the problem of stress should be looked at in depth at individual workplaces.Only after this is done an appropriate and specific stress management programme can be created. he purpose of this present study is to determine the main reasons for and consequences of stress at work, and to find the most effective ways of preventing it and coping with it. The research also analyzes the overall current situation of stress at work and takes a look at some historical facts related to the origins of stress. People from different age groups, working spheres and cultures were invited for the interview during the year 2009, in order to get more information and practical examples from real life situations.
\end{abstract}

Since there wasn't really any specific research found on this topic, my study will be potentially quite useful to companies, especially in the success of their overall development.

\section{Council for Innovative Research}

Peer Review Research Publishing System

\section{Journal: International Journal Of Management \& Information Technology}

Vol . 11, No 1

editorsijmit@gmail.com

www.ijmit.com 


\section{Introduction:}

Anxiety have turned into a critical term in ordinary dialect Tired appearances, disenthralled looks, unwillingness to speak with the partners, steady disappointment and at last the diminishing of the general working results and poor execution these all are originated from anxiety .. The proportion of anxiety is expanded step by step as indicated by the work. Occupation anxiety is the destructive physical and enthusiastic reactions that happen when the prerequisites of the employment don't coordinate the capacities, assets, or necessities of the laborer. Occupation stress matters to our wellbeing and our work. When we feel focused on, our bodies react by raising the grouping of anxiety Hormones in our blood. At the point when our bodies ceaselessly react to Constant requests or dangers, methods for dealing with stress stay in overdrive, which can harm to wellbeing after some time. Exploration demonstrates that over the top occupation anxiety can prompt some long haul wellbeing issues, including cardiovascular infection, diabetes, debilitated insusceptible capacity, hypertension, musculoskeletal scatters, substance misuse, sadness and uneasiness. Anxiety is not generally awful. Anxiety as a test stimulates us mentally and physically, and it inspires us to learn new abilities and expert our work. At the point when a test is met, we feel casual and fulfilled. This is great anxiety or eustress. Be that as it may, in some cases a test is transformed into occupation requests that can't be met. This is negative push, or trouble, which sets the stage for ailment, damage, and employment disappointment. in the event that you work, it is likely that occupation anxiety will influence you sooner or later amid your profession. Whether you are a worker or a business, perceive that stretch in the work environment can add to weakness, which can prompt lower efficiency, non-attendance, and higher social insurance costs.

\section{For instance:}

- Up to $44 \%$ of ladies and $36 \%$ of men need to stop their employments in light of work environment stress. This adds to despondency and also numerous negative wellbeing impacts.

- Healthcare consumptions are about half more noteworthy for specialists who report elevated amounts of anxiety.

- Sixty percent of lost workdays every year can be credited to push.

- Job anxiety is more firmly connected with wellbeing protests than money related or family issues

\section{Goals}

The point of my exploration is to demonstrate the effect of the weight on the work process and the significance of the Stress Management program in the organizations. There are many sorts of anxiety; however there is fixation on JOB STRESS in my theory. I likewise need to characterize all the more precisely, that the postulation theme is not about emergencies administration, which is just discussing representative's anxiety in basic circumstance in the organization.

The formative needs of such an examination are figured in three fundamental reasons:

Counteractive action of anxiety circumstances in the association Reducing the anxiety sway on the work process Deliverance from anxiety at employment place.

The focal destinations of my proposition examination are: to perceive the most continuous reasons of anxiety at work, subsequent to the gigantic measure of the considerable number of reasons is difficult to depict in one theory; to figure out the best approaches to anticipate showing up anxiety and to battle with it, on the grounds that no exploration is so required as the exploration with down to earth bits of advices; and to demonstrate the part of correspondence when discussing anxiety at work.

Point is worth to be inquired about for the most part on the grounds that the issue of anxiety, which means negative impact on work process, happens more frequently. There are a few purposes behind vicinity of such a reality, which I represent in my proposal. Organizations are occupied with figuring out how to oversee and stay away from anxiety. That is the reason every one of the organizations, which think about their future in world business sector, will profit by anxiety administration research.

\section{Writing survey}

In my exploration writing audit perspective that before past study demonstrates the negative effect on work place stress. There is expanding proof which proposes that today like never before; representatives are working in an environment of tension and anxiety. Dominant part people groups are experiencing anxiety in distinctive occupations of classifications they can't control the circumstance and confronting most exceedingly terrible issues throughout their life the pessimistic effect of anxiety can be seen in the extensive variety of conditions that are connected with it. Anxiety has been related not just with an assortment of mental conditions including tension and gloom, additionally with various vital physical conditions including heart assault, ulcers and stroke. It is additionally thought to be a contributing element to low back agony and tedious anxiety wounds.

The World Health Organization (2001) predicts that by 2020, dysfunctional behavior will be the second driving reason for handicap around the world, after coronary illness. The International Labor Organization ((ILO), 2000) says emotional sickness influences more human lives and offers ascend to a more noteworthy misuse of HR than every other type of handicap. Mental disarranges are one of the three driving reasons for inability. In the EU, for instance, emotional wellbeing issue are a noteworthy purpose behind conceding incapacity benefits. Five of the 10 driving reasons for handicap overall are emotional well-being issues - significant despondency, schizophrenia, bipolar clutters, liquor use and fanatical urgent issue - and record for $25-35 \%$ of all incapacity (Cameron, 2000). Businesses are incredibly influenced by their 
representatives' psychological well-being, and managers influence - absolutely or contrarily - their workers' emotional well-being.

The occurrence of anxiety inside of European culture is on the expansion and records for more than $30 \%$ of all nonattendance from work (Paoli, 1997). Confirmation for this is rising up out of various sources including reviews, longitudinal studies and nonattendance measurements (e.g. Van der Hek and Plomp, 1997; Jones et al, 1998). Estimations of the Health and Safety Executive (1998) are that between $30-60 \%$ of all Sickness Absence in the UK is identified with a mental or enthusiastic unsettling influence (i.e. anxiety, burnout). In The Netherlands long haul ailment nonattendance because of 'mental issue's has expanded from $17 \%$ in 1974 to $32 \%$ in 1992 (Allegro and Vermin, 1998). This figure has expanded over the previous decade. Proof from the writing recommends that Workers on long haul nonappearance as an aftereffect of anxiety are less inclined to come back to work than those with physical wounds or ailments (Watson Wyatt, 2000). Watson Wyatt (1998), in their yearly study of incorporated incapacity administration software engineers, found that episodes of inability are progressively identified with gradually creating, ceaseless conditions and work-impelled anxiety. In this review, musculoskeletal issues, for example, carpal passage disorder and dull movement grievances (50 percent) surpassed wounds (44 percent) as the most well-known condition setting off a word related inability cost. The study likewise found that emotional well-being connected inabilities are on the ascent. Forty-five and 58 percent of businesses, separately, communicated developing worry about emotional instability as a wellspring of word related inabilities and non-word related incapacities. Additionally, $33 \%$ of overview respondents described the administration of emotional sickness in the working environment as extremely troublesome. The Canadian Mental Health Association (CMHA) says that passionate pain and dysfunctional behavior represent $20-30 \%$ of all worker truancy and mechanical mischances. Somewhere around 1990 and 1999, a 220-per-penny increment in anxiety cases was accounted for by representative help programs, as per the overseeing chief of the Canadian Institute of Stress (Bauer, 2003). Seventy-nine percent of members in Watson Wyatt's (2002/2003) 'Staying Work Canada' review demonstrated that mental conditions (wretchedness, nervousness, stress and different conditions that influence the mental wellbeing of representatives) were the main source of transient incapacity (STD) claims, while 73 percent affirm that these conditions are likewise the main source of long haul handicap (LTD) claims. The same review evaluated that most organizations burn through 2 to 3 for each penny of their finance on transient incapacity cases, of which half may be push related. A late report from Health Canada (2002) puts the expenses connected with emotional wellness issue in the working environment at about 14 percent of the net yearly benefits of Canadian organizations, with a sticker price of up to $\$ 16$ billion every year. This report likewise proposed that representatives who experience work stress (brought on by interpersonal, work control and administration issues) are six times more probable than others to be truant from work for six or more days.

The United Kingdom Department of Health and the Confederation of British Industry have evaluated that 15 to 30 percent of laborers will encounter some type of psychological wellness issues amid their working lives. The latest examination from the HSE (2002) recommends that since 1995 the quantity of working days lost to push, uneasiness and wretchedness in the UK has dramatically increased. In 2001, more than 13 million days were lost on account of anxiety, which influences one in five of all representatives at an expense of up to $£ 3.8$ billion.

In the USA in 2000 , on any given day $3.9 \%$ of representatives in US workforce are missing from work (Bureau of Labor Statistics, 2002). In 1998 expenses connected with 8.3 million business related wounds and 5,100 work passings brought about 125 million lost work days and cost American business $\$ 125$ billion in compensation and profitability misfortunes, medicinal services costs and managerial costs (Di Guida, 1995). These are the direct quantifiable expenses, be that as it may, they speak to just a part of the expenses. The circuitous expenses, which incorporate the expense of procuring and preparing substitution workers, lost benefits, loss of clients, diminished representative assurance and proficiency, time lost by directors and different representatives at the mischance; are assessed to be around 5 to 15 times higher (Kalina2.)

\section{PRESENTATION OF DATA}

Under this research methodology phase, I tried to present all the data collected by various sources into meaningful form, which is helpful for me after interpreting to draw conclusion.

\section{ANALYSIS OF DATA}

By using all knowledge and skills, I tried to analyze the data. I also got guides from my supervisor and senior class fellows and staff of different banks

- Due to lack of staff in banks some officers are busy and some are not focus towards my questionaries' papers that's why I face some problems .... There were some hindrances in the way of collection of data ... I gave 30 questionnaires to different banks out of $30 \mathrm{I}$ got only 18 questionaries' some are missing and some have lack of response that's why I filled only 18 questionaries' in my research and collect all data in just 18 questions that's the reason of limitations in our research survey 


\section{Data analysis}

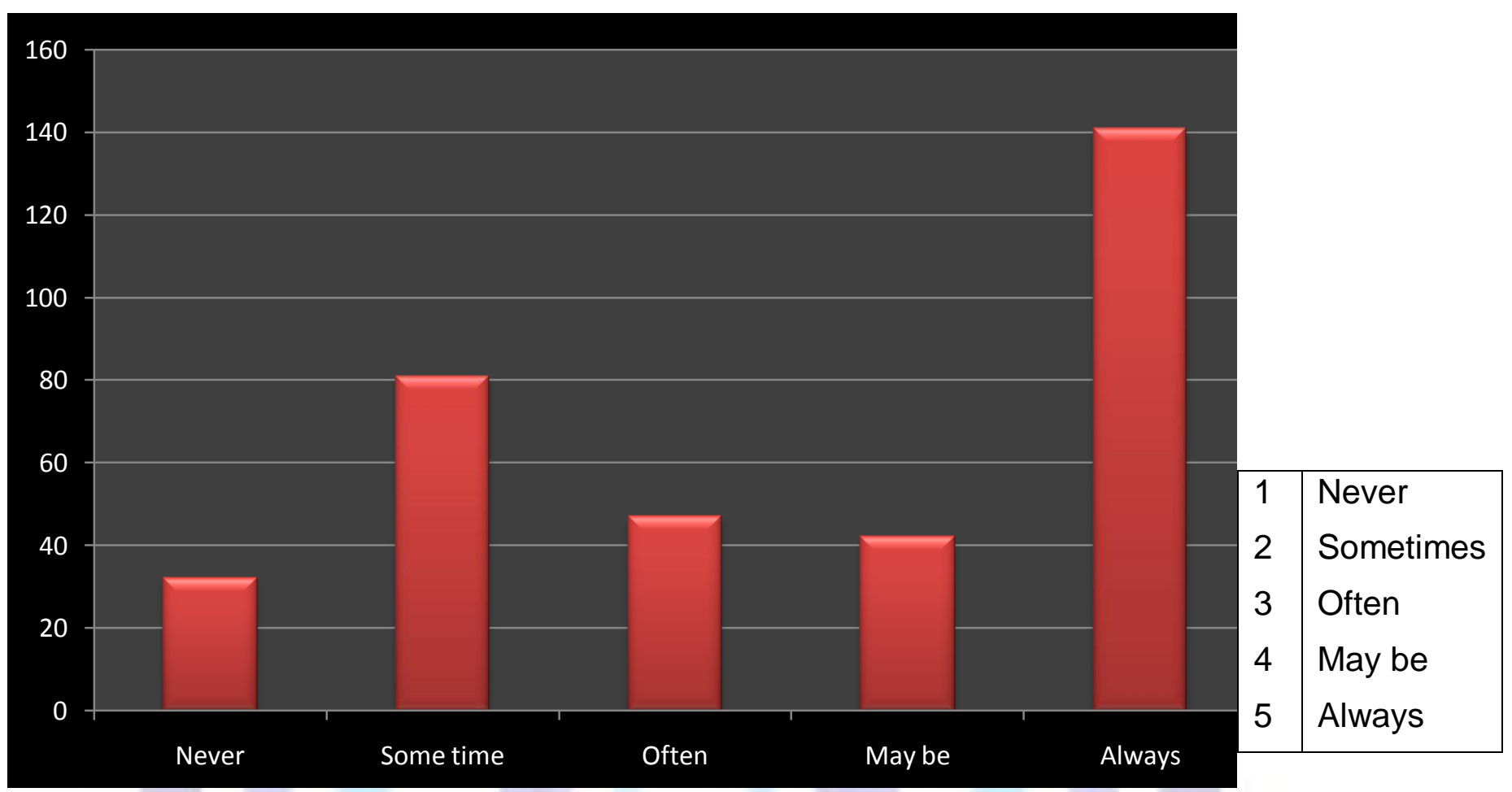

\section{Often 47.77 \\ Never 31 \\ Sometime 90 \\ May be 45.55 \\ Always 155.5}

During my research survey I had sent questionnaires regarding my thesis purpose different banks have different answers to my questionaries' some peoples are choosed never and some are sometimes but majority peoples $r$ choosed always so finally the conclusion of my questionnaire survey is peoples $r$ partially agree to some times and majority agree to always these $r$ the result of my research thesis

\section{Example: which questions are asked by workers in banks that are blow :}

\section{Work stress in banking sectors}

\section{QUESTIONARIES}

1. If work gets difficult, my colleagues will help me

(1 $223 \quad 45)$

2. I am clear what my duties and responsibilities are

3. I feel huge pressure on myself when I work for long hours (1 23345 )

4. I have to work very fast because of many assignments

$\left(\begin{array}{lllll}1 & 2 & 3 & 4 & 5\end{array}\right)$

5. If $i$ were aware of bullying I would be able to challenge it (1 12344 )

6. I can rely on my senior manager to help me out with any work problem (1 23345 )

7. I receive the respect at work that I deserve from my colleagues

8. I am clear about the goals and objectives of my department

9. I am unable to take sufficient break due to the work load

10. I have to choice in deciding the work that will be done by me

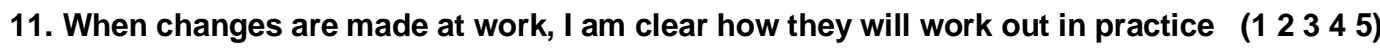

12. I am supported through emotionally demanding work 
13. I am subject to personal harassment in the form of unkind words or behavior

14. I am encouraged on the work I do

15. My company makes me feel valued

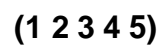

16. I am so much busy that my personal and family time is also utilize towards work(1 2345 )

\section{Sometimes I feel unpleasant and dangerous physical conditions}

18. I understand how my work fits into the overall aim of the organization

Such expressive cases are noble purposes for pondering utilizing Stress Management Programs for tackling specific kind of organization's issues. Notwithstanding, cases of prestigious firms don't generally mean huge aggregates of cash, center or little organizations ought not be perplexed, there are many diverse sorts of projects and strategies for their execution, which are genuinely modest. Every interest in representatives is constantly adjusted, and there is a chance to be revamped even in twofold or in treble times.

\section{Counteractive action and battling with anxiety at work}

While some work environment anxiety is typical, over the top anxiety can meddle with your efficiency and effect your physical and enthusiastic wellbeing. Furthermore, your capacity to manage it can mean the contrast between achievement or disappointment. You can't control everything in your workplace, however that doesn't mean you're weaknotwithstanding when you're stuck in a troublesome circumstance. Discovering approaches to oversee work environment anxiety isn't about rolling out immense improvements or reevaluating vocation aspirations, yet rather about concentrating on the one thing that is dependably inside of your control: you.

\section{Adapting to work stress in today's dubious atmosphere}

For laborers all around, the harried economy might feel like a passionate crazy ride. "Cutbacks" and "spending plan cuts" have ended up apothegms in the working environment, and the outcome is expanded trepidation, vulnerability, and larger amounts of anxiety. Since occupation and work environment stress increment in times of monetary emergency, it's imperative to learn new and better methods for adapting to the weight.

Your feelings are infectious, and anxiety affects the nature of your connections with others. The better you are at dealing with your own particular stretch, the more you'll emphatically influence everyone around you, and the less other individuals' anxiety will adversely influence you.

\section{Deal with yourself.}

The issue with employment stress it can make individuals wiped out, both mentally and physically, as per Beehr, who ponders work stress and fulfillment. So a successful approach to stretch less is to work on diminishing this strain.

For one, you can look for expert help for your manifestations from specialists or therapists, he said. Additionally, you can take part in exercises that are unwinding to you, for example, yoga, or anything that you truly appreciate, for example, meeting with companions, perusing, staring at the TV or cultivating, Behr said. Obviously, physical exercises are an aid to your wellbeing - and can be defensive. Being "in great physical quality" likewise "makes you to some degree more invulnerable to impacts of anxiety."

\section{Movement your mentality.}

In her book, Hess discusses making a Professional Paradise, which she sees as a perspective - not the ideal business or paycheck. So it isn't what really happens at work however how we see occasions that matters.

She alludes to any occasion that evokes a negative response, for example, pity or dissatisfaction, as a POW, and anything positive as a WOW. She isolates POWs into outside - , for example, feedback from the supervisor - and inner -, for example, pummeling yourself (and does likewise with WOWs). The objective is to "attempt to minimize the inward POWs, deal with the outer POWs and expansion the inner WOWs," Hess said.

Hess has added to a 5-stage approach for simply that, which she calls SHIFT. Here's the breakdown:

- $\quad$ Stop and take a full breath, an activity that Hess said we simply don't do what's necessary of. This quiets you down, as well as keeps you from saying something you may lament.

- $\quad$ "Harness your unsafe automatic responses," which is basically your battle or flight reaction. At the point when something adverse happens, a few individuals rationally pull back from the circumstance, while others go on edge and lash out. Another negative automatic response is stress, Hess said. Case in point, say your most loved director commonly dresses calmly however today he's wearing a suit. Your automatic response is to accept that he's talking for another occupation. Since automatic responses appear to be programmed, it's regularly difficult to pinpoint them. To remember them, Hess recommended asking others. "In the event that I don't understand my automatic is to be additionally controlling when I'm focused, that'Il be hard for me to understand that," Hess said. So she requests that her family hold her under wraps. Asking colleagues is another alternative. At the point when Hess worked at a healing center, she consistently conversed with her chief, which stayed up with the latest on organization data. Amid workforce gatherings, she'd unwittingly tap her pencil out of fatigue. Luckily, one of Hess' great companions advised her, and she quickly ceased. Another simple approach to spot examples is to simply watch your responses when you're pushed. 
"Identify and deal with your negative feelings," Hess said. Pause a moment, and consider how you're feeling. It additionally recognizes "where these feelings are confirm in your body" and make sense of what helps you "without giving it much thought," whether that is listening to your iPod or going out for a stroll.

- $\quad$ Find new alternatives. To do that, Hess recommended "the Rule of Three." Ask yourself these three inquiries: What has worked previously? What might somebody I appreciate do? What might somebody objective do?

- Take one positive activity. This could be as straightforward as discovering the amusingness in a circumstance, Hess said. Consider, in what capacity would I be able to take a gander at this circumstance in an unexpected way? In case you're overpowered with a task, a positive step is to make a rundown, separating it into sensible parts.

\section{Intention your worries.}

Pinpoint your wellsprings of anxiety, and consider how you can resolve these worries, Beehr proposed. Case in point, in case you're pushed around an undertaking, consider who could clear up the degree and required assignments. On the off chance that it's a contention with an associate, consider what you can do to determine it. Essentially, the key is to take a critical thinking approach and attempt to alter what's inside of your energy.

\section{Practice appreciation.}

Hess proposed contemplating one thing you're appreciative for consistently at work - regardless of the fact that it's as basic as being grateful that your manager purchases filtered water for the workplace. Each time something great happens at work, record it. Toward the day's end, you may be shocked how frequently well done really happens. As Hess said, "we have a tendency to recollect the one POW rather than the 10 WOWs." You can even have your colleagues offer what they're appreciative for. Hess has seen chiefs do this at workforce gatherings.

On a related note, spread the affection. Hess urged perusers to accomplish something pleasant for their colleagues, for example, leaving them a treat.

\section{Hang with an incredible group.}

The general population at your employment can bigly affect your level of fulfillment. Numerous working environments have what Hess termed the "bunch of convicts," associates who are continually worried and do a considerable measure of griping. Rather, hang out with individuals who are steady, casual and only enjoyable to be around.

An awesome gathering of collaborators likewise can help with a substantial workload or simply give moral backing. Interestingly, however, social backing isn't generally useful, as per Beehr's exploration. "Now and then individuals will help us when we don't need it," or their assistance infers that we're second rate, he said.

Social bolster should be given unreservedly - so there's no commitment for the individual to give back the assistance and from an associate viewpoint, not on account of you're predominant.

6. Reconnect with what you adored about your occupation. Hess proposed asking yourself: "What is great about my occupation? How am I offering some person?" Some assistance with making the "association with quality of yours or a path in which you're having any kind of effect," she said. "A great many people are more fulfilled in the event that they have an occupation that they see as important and allows them to utilize a considerable measure of their abilities that they esteem," Beehr said. This is particularly genuine if an individual uses their abilities for a whole venture, for example, composing a report versus contributing only one section, he included.

\section{Conclusions}

The anxiety turned out to be a piece of regular life for the cutting edge society. It influences our way of life and the results of the correspondence. That is the reason for the organizations and utilized individuals, who think about the work effectiveness and own prosperity, my examination is significant. The exertion which is expected to perform the assignments to avert anxiety mediation appears to be colossal. Be that as it may, once an organization or a man tries, the achievability of the examination gets to be sensible; besides time and cash spent get to be adjusted. Banks began pondering the representatives' prosperity at working place generally not very far in the past, and additionally Stress Management was created as of late in past years. Along these lines the exploration is very cutting edge and is of high need. In addition a percentage of the outcomes are truly startling and new, and the outcomes which correspond with past looks into's outcomes demonstrate their unwavering quality. On the other hand, in the ebb and flow minute, there are just a couple looks into on the point of Stress at work and Stress Management which are accessible outside some particular mental organizations or are for nothing out of pocket. While making the exploration I have not just got new, intriguing and valuable data, which I would not acquire from somewhere else, but rather likewise met a great deal of new superb individuals, with whom I would not have an opportunity to talk in conventional circumstances. As I would like to think the examination is helpful for the banks, as well as presents the thoughts for further looks into. Such issues as aversion, lessening and battling with anxiety can be considered more profound independently and exhibited as individual looks into. In addition there can be an examination made particularly on the theme about anxiety brought about by rejection, what to say the individual and how to help him, if will be released. Actually I fulfilled by my work all that much and it was an extraordinary delight to examine the point, in which I am extremely intrigued. I feel that the learning I have will be helpful for the understudies 


\section{Bibliography}

1. Abbott, A. 2001. Chaos of Disciplines. United Kingdom.

2. Agrawal, R. 2001. Stress in life and at work. Response Books. London.

3. Bickerstaff, L. 2007. Stress. Rosen Publishing.

4. Lynn and Corbidge. Business Costs.1997

5. Cox, T 1978. Stress. University Park Press. Baltimore.

6. Dewe, P. 2002. Stress. A brief history. Blackwell Publishing. United Kingdom.

7. Sauter S, Hurrell J, Murphy L, Levi L. 1997 Encyclopedia of Occupational Health and Safety. Stellman J. 1997. Psychosocial and organizational factors.

8. Northwestern National Life. 2009. Insurance Com.

9. Alice Adams, Andrew. 2003. Ryder a survival guide.

10. Ben Martin, Stress and personality, PSY.D. 2006

11. United States National Institute of Occupational Safety and Health, Cincinnati, 1999

12. University Laval -Chair in occupational health and safety managementll.2002

13. Guidance on work-related stress: Spice of life - or kiss of death, European Commission, Directorate-General for Employment and Social Affairs, 1999

14. Managing stress at work: Discussion document, United Kingdom Health and Safety Commission, London, 1999

15. Main State Nurses' Association. ProQuest Information and Learning Company. 2003

16. Jones JW, Barge BN, Steffi BD, Fay LM, Kuntz LK, Wuebker LJ, 1988. Stress and medical malpractice: organizational risk assessment and intervention. Journal of Applied Psychology. Gentle stress relief for Peace Health and Happiness. URL: http://www.gentle-stress- relief.com/stress-prevention.html. Quoted: 30.09.2009

17. Source: http://psychcentral.com/lib/6-ways-to-stress-less-at-work/0007478

18. Job Stress Management Resources. URL: http://www.mindtools.com/stress/Brn/IntroPage.htm. Quoted: 10.01.2010

19. Mental Health Touches. Stress at work.URL: http://www.athealth.com/Consumer/disorders/workstress.html. Quoted: 30.12.2009

20. CSL cartoons. Stress at work cartoons. URL: http://www.cartoonstock.com/directory/s/stress_at_work.asp. Quoted: 25.08.2009

21. Stress Management in Russia. URL: http://stress.depressii.net/. Quoted: 28.10.2009

22. BNet. Business Management. URL: http://i.bnet.com/blogs/stress2.jpg. Quoted: 12.10 .2009

23. Eurofound. SurveyReports. EWCO . European Working Conditions Observatory. URI:http://www.eurofound.europa.eu/ewco/surveyreports/BE060601SD/be060601sd- fig01.jpg. Quoted: 13.11.2010

24. CSA Consulting. Business Consulting. URL: http://www.csaconsulting.biz/lmages/Conflict\%20Picture.gif. Quoted: 25.11.2009

25. Princeton Survey Research Associates. URL: http://www.psrai.com/. Quoted: 12.02.2010

26. Causes of the stress wheelll Team Technology. 1995 URL: http://www.teamtechnology.co.uk/tt/t-artic//stressmanagement-pt2.htm. Quoted: 29.02.2010

27. IQ Matrix. URL: http://iqmatrix.com/. Quoted: 15.01 .2010

28. Absolute astronomy. Stress Management. URL: http://www.absoluteastronomy.com/topics/Stress_management. Quoted: 14.12 .2009

29. ATHRITIS Foundation. URL: http://www.arthritis.org/10-steps-to-stress-relief-.php. Quoted: 02.02.2010

30. Not alone. Stress at work. URL: http://www.enotalone.com/article/6995.html Quoted: 03.12.2009 http://www.absoluteastronomy.com/topics/Stress_management

31. Cartwright, S and Cooper C.L. (2002). ASSET: An Organizational Stress Screening Tool - The Management Guide. Manchester, RCL Ltd.

32. Tytherleigh, M.Y., Webb. C., Cooper, C.L. and Ricketts, C. (2005). Occupational stress in UK Higher Education Institutions: a comparative study of all staff categories. Higher Education Research \& Development, Vol 24:1, pp $41-61$.

33. Management standards [HSE]

34. Evaluating risk using the HSE management standards 